\title{
EL OCASO DE LA MISIÓN JESUITA DE JAPÓN A TRAVÉS DE MARTIN SCORSESE: SILENCE (2016)
}

Kevin DÍAZ ALCHÉ

Universidad de Alicante

\section{RESUMEN}

En los ámbitos de la divulgación y el entretenimiento occidental, la imagen que se transmite sobre las culturas ajenas a la nuestra suele estar cargada de expresiones poco representativas. Dentro de este grupo, Japón es, como se ha estudiado en multitud de ocasiones, un ejemplo que ha ido evolucionando a lo largo de la Historia del Cine. En este texto se analiza el caso de Silencio (Martin Scorsese, 2016), obra que trata de poner de relieve el ocaso del primer intento por establecer relaciones estables entre el archipiélago nipón y el continente europeo a través de la Compañía de Jesús.

Palabras clave: Siglo XVII, Compañía de Jesús, choque cultural, sincretismo, cine.

\section{ABSTRACT}

In the fields of occidental outreach and entertainment, the image which is transmitted about alien cultures is usually filled with unrepresentative manifestations. Within this group, as it has been studied, Japan is an example that has evolved throughout history of cinema. In this text it is analysed the case of Silence (Martin Scorsese, 2016), work that tries to highlight the twilight of the first attempt to stablish a stable relationship between the Japanese archipelago and the European continent though the Society of Jesus.

Keywords: $17^{\text {th }}$ Century, Society of Jesus, cultural shock, syncretism, cinema.

\section{INTRODUCCIÓN}

En los ámbitos de la divulgación y el entretenimiento occidental, la imagen que se transmite sobre las culturas ajenas a la nuestra suele estar cargada de estereotipos, cuando no de un supuesto folklore poco representativo. Japón es, como se ha estudiado en multitud de ocasiones, un caso característico de esta situación. Sin embargo, hasta el siglo XVI, las alejadas tierras de Japón solo eran para Europa un desconocido rincón dentro del confuso conglomerado de exóticas regiones ubicadas más allá de las fronteras del Imperio Otomano. 
Ante el inmenso vacío de referencias acerca del Extremo Oriente, la excepción se imponía, sin embargo, mediante tímidos comentarios escritos por viajeros como Marco Polo. El veneciano no llegó a pisar el archipiélago nipón y, además, de entre todos sus relatos recogidos en II Milione, la breve alusión a Zipango sólo sirvió para acrecentar una visión distorsionada de la realidad. Con toda probabilidad, había recibido noticias a través de terceros, alimentadas por el misticismo y repletas de narraciones fantásticas. La única información que se poseía sobre sus características geográficas, economía y sociedad afirmaba que se trataba de «una isola in levante, ch'è ne l'alto mare 1.500 miglia» habitada por una población autogobernada de tez pálida y donde se hallaba una gran cantidad de oro desaprovechado y dispuesto a ser explotado por quienes tuviesen el valor y la capacidad de pisar sus orillas (Polo, 1975: 133).

Esta situación de incertidumbre y desconocimiento es aplicable a casi todo Oriente, un concepto eurocéntrico que plantea una barrera fundamentalmente mental, social y cultural entre los territorios situados en Europa y aquellos al este de las orillas mediterráneas. Una tierra que, usando la expresión seguida por el profesor Miguel Corrêa Monteiro, para los habitantes de la cristiandad europea estaba repleta «de mitos e de fantástico, mas também de ciladas, onde os cristãos não se deviam aventurar» (2006: 67). Un mundo que los imperios coloniales de Castilla y-sobre todo- Portugal comenzaron a abrir a partir del siglo XVI. Para el caso de Japón, la Compañía de Jesús protagonizó el primer contacto cultural en 1549, cuando Francisco Javier desembarcó en Kagoshima y asumió «a responsabilidade da propagação da fé através da palavra e do exemplo» (Corrêa, 2006: 43). De este modo la Misión de Japón ha de ser considerada como génesis de las primeras relaciones entre Occidente y el archipiélago nipón. El hecho es que la presencia hispano-portuguesa en general y jesuita en particular supuso un intercambio de ideas y formas de pensar entre Oriente y Occidente que impactó a Europa tras la divulgación del mundo que los misioneros encontraron. Mediante una extensa correspondencia, los misioneros que llegaban informaban de la situación del archipiélago, aunque con un cierto discurso evangelizador y paternalista que no permitía a los novicios llegar con una idea exacta de la realidad nipona.

Francisco Javier, a los pocos meses de su estancia, ya se atrevía a decir que esta sociedad era «la mejor que hasta agora esta descubierta», tanto que «entre gente infiel no la hallava otra que a los lapones haga ventaja» (Barreira, 1552: 22). Después de dos siglos, Japón era una realidad palpable y, al mismo tiempo, lejana y confusa. Además de la correspondencia y las publicaciones propagandísticas de la propia Compañía de Jesús, Japón se abrió paso por otros medios de divulgación asociados al entretenimiento. Tanto en literatura como en teatro, autores contemporáneos trataron el acontecimiento en sus obras. Destacamos al maestro dramaturgo Lope de Vega, autor de Triunfo de la Fee en los reynos del Japón (1618), un escrito centrado en los primeros momentos de gran optimismo y fervor religioso y en los posteriores procesos de martirio sufridos por misioneros y comunidades bautizadas en Japón ${ }^{1}$ tras el cambio de rumbo en la política interna. Le siguen una serie de obras, todas ellas bajo un cariz profundamente religioso, tales como Relación de los mártires del Japón (Ruiz Vega, 1623) y Christiandad del Japon, y dilatada persecución que padecio (Sicardo, 1698). Como resultado del cambio de rumbo del Shogunato, la implantación del sistema

1 Siguiendo la tesis seguida por el profesor João Paulo Oliveira e Costa, insistimos en el concepto de «bautismo» sobre el de "conversión», pues, como señala el investigador, «it is useless to try to define an "effective conversion" or to try to demonstrate the failure of missionary work with bad examples of "converted people" [...]. We cannot evaluate a "success", especially if we focus upon the "quality" of the conversions» (2003: 46). Tal reflexión nos hace considerar que el término «bautismo» se ajusta mejor a su perspectiva histórica. 
sakoku-rei ${ }^{2}$ y el consecuente cierre y aislamiento del país, las noticias desaparecieron. De ahí que, desde entonces, las obras publicadas en suelo europeo quedaran circunscritas al arquetipo de la narración religiosa con textos como Informaciones acerca de la vida del Venerable fray Alonso Orozco, 1601-1700 (de Gante, 1719); The history of the church of Japan (Crasset, 1705); y The history of Japan (Kaempfer, 1727).

Esta tendencia es modificada significativamente en el último tercio del siglo XIX, tras la apertura de Japón. De los viajes al archipiélago con el objetivo de aprender de una cultura que se había mantenido hermética a las influencias externas nacieron los primeros estudios antropológicos e históricos, como El imperio del sol naciente (Lucena, 1893) y A history of the Japanese people from the earliest times to the end of the Meiji era (Brinkley, 1915).

\section{JAPÓN EN EL SIGLO DEL CINE OCCIDENTAL: HACIA UN MAR DE ESTEREOTIPOS}

Con la llegada del celuloide, llegan también cambios en la imagen que Occidente tiene de Japón. No sólo por los evidentes avances tecnológicos o la democratización del consumo de productos de la industria cinematográfica, sino también por los cambios sociales, culturales y políticos del público receptor y su entorno. Diferenciamos así dos grandes períodos en lo relativo al cine que evoca una imagen de la cultura nipona.

El primero de ellos lo situamos previo al término de la II Guerra Mundial. Se trata de un cine de corte militarista y propagandístico, ligado al desarrollo del conflicto bélico y, especialmente, la intervención de Estados Unidos y Canadá en el Frente del Pacífico (19411945). No es nuestro propósito realizar una recopilación exhaustiva, por lo que aludimos a referencias paradigmáticas. Es el caso de algunos cortometrajes que forman parte de la serie canadiense Canada Carries On, producida por la National Film Board of Canada entre 1940 y 1959. Destacamos, de toda la relación, Warclouds in the Pacific (Legg, 1941). Estrenado unos días antes del ataque a Pearl Harbor y nominado al Óscar al mejor documental corto, en él se expone la perversión ideológica que se afirma estar ocurriendo en Japón y advierte que Canadá está preparada en caso de guerra en el Pacífico ${ }^{3}$. Por su parte, en los Estados Unidos de América la labor propagandística fue encomendada al cineasta Frank Capra, quien ya había sido galardonado con un Óscar al mejor argumento por Caballero sin espada (1939). En relación a Japón, de su obra sobresalen dos filmes pertenecientes a la serie de largometrajes propagandísticos Why We Fight, que son Prelude to War (1942), premiada con un Óscar al mejor documental y donde se expone el adoctrinamiento y militarismo japonés; y The Battle of China (1944), en el que se victimiza a la nación y al Estado chino ante un exacerbado fanatismo japonés. Pero la obra que mejor ejemplifica este tipo de cine es, sin duda, Know Your Enemy - Japan (1945). Tratando de hacer un recorrido por la historia militar de Japón, el documental construye una imagen despectiva de la sociedad nipona y anima a la intervención militar en suelo japonés ${ }^{4}$. Este tipo de obras ha ido evolucionando y

2 "Isolationist policy", applied from 1639 to 1868, under which relations with European countries was forbidden on pain of death (with the exception of the Dutch on the islet of Dejima in Nagasaki) and relations with Asian countries were strictly controlled by the government» (Frédéric, 2002: 813).

3 Información extraída de la ficha del cortometraje desde los sitios web IMDb y de la National Film Board of Canada, disponibles en: https://www.imdb.com/title/tt0034372/?ref_=ttawd_awd_tt y http://www.nfb.ca/film/ warclouds_in_the_pacific/, respectivamente. [Fecha de consulta: 16/02/18].

4 Información extraída de las fichas ubicadas en los sitios web IMDb y RottenTomatoes, disponibles en: https://www.imdb.com/title/tt0184254/?ref_=nm_flmg_dr_16, https://www.imdb.com/title/tt0185405/, y https:// www.rottentomatoes.com/m/know_your_enemy_japan/. [Fecha de consulta: 25/04/18]. 
adaptándose a los principios de la sociedad de consumo y el Nuevo Hollywood con películas como Pearl Harbor (Bay, 2001), donde se llega a deshumanizar la presencia japonesa en una visión comercial que "presenta la estructura héroe versus antihéroe dentro de la trama principal» (Rosillo, 2016: 710).

El segundo grupo despega a partir de la década de 1960 y está relacionado con la cultura de masas. La nueva dinámica del cine comercial occidental se aproxima a Japón teniendo en cuenta dos conceptos definidos por Laura Rosillo, la proyección condicionada y la variable receptividad. Siguiendo con la autora, la proyección condicionada responde a la interpretación que la dirección del film hace de la cultura nipona, «realizando una proyección sucesiva de imágenes en las que se advierten de forma subyacente unos tópicos comunes. En este momento, la cultura japonesa se impregna de unos estereotipos que condicionan o restringen el patrimonio japonés a una serie de ideales». La variable receptividad, por otro lado, se da cuando la proyección es captada "por un espectador occidental, generalmente ajeno a la cultura nipona, que interpreta de forma variable e insegura unos códigos insertos en las imágenes proyectadas» (2006: 708). Población europea y norteamericana, atraída no sólo por las tradiciones, sino también por otros referentes clásicos, condicionan su visión construida a través del cine (Barrenetxea, 2008: 139), procedimiento que responde a «una concepción de la cultura japonesa "occidentalizada"» (Rosillo, 2006: 708) y que, igualmente, ha creado personajes estereotipados que Francisco Javier López sintetiza en un total de seis, a saber, el ejecutivo, el samurái, el yakuza, el maestro, la geisha y la ama de casa (2010: 1544-1551).

Dentro de este grupo, siguiendo la imprenta del Nuevo Hollywood y como parte del cine comercial, se encuentra Silencio (2016), adaptación cinematográfica de la novela histórica bajo el mismo nombre escrita por Shūsaku Endō(1966), dirigida por Martin Scorsese. Un film que hemos seleccionado por representar un caso de acercamiento a la cultura japonesa a través de un estudio cultural con el objetivo de plasmar, en la gran pantalla, las diferencias habidas en las estructuras mentales de la población europea y japonesa del siglo XVII, rompiendo con las líneas vistas hasta ahora en cuanto a un acercamiento arquetípico.

\section{PRODUCCIÓN Y OBJETIVOS DE SCORSESE}

Hablar de este largometraje es referirse a un largo proceso de meditación, negociación y final producción de un proyecto que Scorsese había deseado sacar a la luz desde finales de la década de 1980, poco después de que el director estrenara La última tentación de Cristo (1988), otra adaptación de la novela homónima de Nikos Kazantzakis publicada en 1955 que le valió una nominación al Óscar a mejor dirección, pero que fue criticada por ciertos grupos conservadores por su visión de la vida de Cristo. Ese mismo año, Scorsese recibió una copia de la novela de Endō de la mano del obispo de la Diócesis de Nueva York, Paul Moore, y, como él mismo reconoció, la leyó durante el rodaje de Los sueños de Akira Kurosawa (1990), en Tokyo.

La producción de una adaptación estuvo en los planes de Scorsese desde entonces. Jay-Cocks presentó un guion e iniciaron algunas negociaciones con Cecchi Gori Pictures que no prosperaron. En 1997 se estrenó Kundun, el segundo de los filmes espirituales del director, por lo que se reanudó el proyecto de rodaje. Nuevamente se sucedieron constantes imprevistos que imposibilitaron que se materializase, entre los que destaca la falta de financiación. Unos años más tarde llegaron títulos como Al límite (1999), El aviador 
(2002) y Gangs of New York (2002), este última valiéndole diez nominaciones a los Oscars y dos galardones en los Globos de Oro, a mejor director y a mejor canción original. Sólo en 2014 comenzó el proceso de producción, partiendo de un guion escrito por Jay-Cocks en 2006 y tras varias disputas legales con Cecchi Gori Pictures ${ }^{5}$. Scorsese entonces se involucró personalmente en la financiación del film, viajando a Cannes en busca de inversores. Con la mayoría del presupuesto asegurado, se cerró el reparto definitivo. En enero de 2015, arrancaba el rodaje en Taiwán y Silencio se convertía en el siguiente trabajo del director desde El Lobo de Wall Street (2013) ${ }^{6}$.

Con todo, el filme se aguardaba con cierta expectación. No sólo por la trayectoria del cineasta, sino también por cómo se había puesto de relieve en las campañas publicitarias el esfuerzo técnico y el significado que iba a tener para el propio Scorsese, quien completaría la que ya es su trilogía espiritual. Los vídeos promocionales ofrecieron los exóticos paisajes de Taiwán, sus playas prácticamente vírgenes y sus frondosos bosques; en definitiva, similares a los que podían encontrarse en Nagasaki (Japón), primera opción de Sorsese para el rodaje. El que el realizador no eludiese la afirmación de que el filme iba a suponer una analogía con respecto a sus experiencias vitales tras haber abandonado la vía del sacerdocio y haberse dedicado en exclusiva al cine captó cierta atención entre el público general y la crítica especializada. Como él mismo dijera, ya había trabajado el tema relativo al abandono del ego en beneficio de la comunidad en Malas calles (1972), pero ahora prometía profundizar en las diferencias culturales y religiosas con el asesoramiento del Padre James Martin, S.J. Del reparto destacan actores con trayectorias consolidadas como Liam Neeson (Padre Cristóvão Ferreira), que ya había trabajado con el cineasta en Gangs of New York (2002), y otros que comenzaban a despuntar en Hollywood como Andrew Garfield (Padre Sebastião Rodrigues) y Adam Driver (Padre Francisco Garupe), lo que hizo el resto ${ }^{7}$.

Tras el estreno mundial en el Vaticano que contó con la presencia del Papa Francisco ${ }^{8}$, la recepción, sin embargo, fue dificultosa. En parte por tratar un tema con escasa repercusión mediática, pero también por la dualidad entre la crítica especializada, que abarca posturas tan dispares que la señalan tanto como la mejor obra de Scorsese como por ser tediosa?. Quizá como motivo de lo primero se dio la contradictoria situación por la que, mientras que la cinta recibió un total de 52 nominaciones de diferentes academias y organismos de cine, entre ellas la del Oscar a mejor fotografía, tan sólo consiguió recaudar 23,7 millones de dólares para una inversión de un total de 46 millones $^{10}$. Datos que reflejan que Silencio

5 Información extraída del sitio web IMDb, disponible en: https://www.imdb.com/title/tt0490215/. [Fecha de consulta: 27/01/18].

6 Información extraída desde el sitio web de la revista Fotogramas, disponible en: http://www.fotogramas. es/Peliculas/Silencio/El-evangelio-segun-Martin. [Fecha de consulta: 05/04/18].

7 Información extraída de varias entrevistas a Martin Scorsese distribuidas por Grupo Planeta como parte del material promocional del filme e indexadas en el sitio web de alojamiento de vídeos Youtube y disponibles en: https://www.youtube.com/watch?v=mocVNjz2nys y https://www.youtube.com/watch?v=BsAK4WkIBxO. [Fecha de consulta: 13/02/18].

8 Información extraída del artículo publicado en el sitio web del diario El País el 1 de diciembre de 2016, disponible en: https://elpais.com/cultura/2016/12/01/actualidad/1480559747_950824.html. [Fecha de consulta: 02/05/18].

9 En el primero de los casos, encontramos la crítica de Richard Brody para The New Yorker, mientras que en segundo destaca el análisis de Manohla Dargis para The New York Times, ambas disponibles en: https:// www.newyorker.com/culture/richard-brody/martin-scorsese-tests-his-limits-in-silence y https://www.nytimes. com/2016/12/22/movies/silence-review-martin-scorsese.html, respectivamente. [Fecha de consulta: 24/01/18].

10 Información extraída del sitio web IMDb, disponible en: https://www.imdb.com/title/tt0490215/. [Fecha de consulta: 27/01/18]. 
no dejó indiferente a nadie, tanto por la temática de la trama como por el enfoque con el que abarca un proceso con una profundidad de lo más compleja.

\section{UN ARGUMENTO JESUITA}

Como filme histórico, Silencio interpreta acontecimientos reales del pasado de gran trascendencia en las relaciones entre Europa y Japón y la evangelización de Oriente. Proceso histórico que se inserta en la Misión de Japón, que parte desde la llegada de Francisco Javier en 1549 y perdura hasta mediados del siglo XVII. La trama centra su atención en un caso particular dentro de las consecuencias de la expulsión de todos los misioneros decretada en varias ocasiones entre 1587 y 1614, convencido el Shogunato de que la moral cristiana «no compaginaba con el régimen feudal que estaba construyéndose» (Kondo, 1999: 184). La respuesta fue, como es sabido, la permanencia en el territorio a pesar de las amenazas, algo que los misioneros expresaron en su correspondencia porque «no combenia yrnos de Japon desanparando a tantas almas» (Gómez, 1588: 711), lo que derivó en una lenta y dura persecución tanto de aquellos que permanecieron como de las comunidades católicas.

El argumento, dentro de estos límites históricos, se centra únicamente en el caso de la apostasía del Padre Ferreira y, con ciertas licencias históricas, los misioneros que marchan al archipiélago en su búsqueda durante la década de 1630. Sólo una misiva del misionero caído resume la situación previa a la llegada de los dos jóvenes. Una escena que se funde con la voz de un pesimista y anacrónico (falleció en 1606) visitador Valignano (Ciarán Hinds), quien en otro momento redactase su Historia del principio y progresso de la Compañía de Jesús en las Indias Orientales (1542-64) (Valignano, 1944) con la intención de contar «la pura verità delle cose» (Lisón, 2005: 83) y que queda aquí reducido a asumir la función de permitir el viaje de rescate. A partir de entonces la trama se centra en los dos jóvenes, Rodrigues y Garupe, quienes, después de que a primera vista nos llame la atención su delgadez ${ }^{11}$, pasan a dar muestras de representar dos formas de entender la religiosidad. El primero muestra una faceta ciertamente probabilista que se deja ver al aceptar el modo herético con el que la comunidad de fieles ocultos vivía el catolicismo o al recomendarles que, en caso de ser necesario, pisen el fumi-e ${ }^{12}$. Su laxitud le hace chocar ocasionalmente con Garupe, cuyo rigorismo le impulsa a rechazar cualquier desviación de la correcta conducta católica de Trento. Ellos mismos representan, a fin de cuentas, la antigua controversia alrededor de cómo dirigir la evangelización de Japón que se materializó con el enfrentamiento entre el método adaptativo de Valignano y la rectitud e intransigencia del superior Francisco Cabral (Ruiz, 1587: 5v). El relato de ambos pronto pasa a ser el de Rodrigues cuando ambos jesuitas se separan, quedando el de Garupe en el mundo de la elipsis para aparecer de nuevo en pantalla una última vez.

Llegado el punto de clímax argumental, en una escena cargada de tensión, Rodrigues renuncia a su fe para así poder recuperarla. Es la gran diferencia con respecto a la novela de Endō pues, en ésta, el jesuita comprende que la religiosidad tiene diversas maneras de

11 Información extraída de varias entrevistas a Martin Scorsese distribuidas por Grupo Planeta como parte del material promocional del filme e indexadas en el sitio web de alojamiento de vídeos Youtube y disponibles en: https://www.youtube.com/watch?v=mocVNjz2nys. [Fecha de consulta: 13/02/18].

12 «Religious images, crucifixes, etc. which were to be trodden upon by the people at the taking of the census, in order to prove that they did not belong to the proscribed Catholic religion» (PAPINOT, 1964: 109). 
interpretarse, distintas incluso a los dogmas dictados desde Roma. Scorsese, en cambio, decide hacer de Rodrigues un mártir que sacrifica su propio destino para mantener vivo el catolicismo japonés con su presencia, lo que hace de la adaptación un viaje intimista por el que el director refleja su propia experiencia espiritual.

\section{HACIA EL ANÁLISIS DE LA MISIÓN DE JAPÓN A PARTIR DE SILENCIO}

Aunque el centro de la historia nos sitúe en los pensamientos de un jesuita, lo que más debe llamarnos la atención y donde al mismo tiempo Silencio peca de escaso desarrollo, es en el contexto en que se mueve el filme. A fin de cuentas, referimos al verdadero protagonista y motor de todas las decisiones tomadas antes y durante la obra: la misión jesuita de Japón y los elementos que afectaron a su desarrollo. Sin la intención de enumerar una completa relación de cuestiones sobre el tema ${ }^{13}$, mencionaremos algunas de especial trascendencia.

Es el caso del referido como método acomodaticio de los jesuitas y que, aunque puede intuirse a través de los actos de Rodrigues, en el filme pasa prácticamente desapercibido, quedando ciertas huellas visibles sólo para personas iniciadas. El hecho es que, desde tiempos de Francisco Javier en Japón (1949-1451), la Compañía entendió que estaban ante una realidad bien distinta de la europea. Había que «buscar mucha humildad [...] y disponernos a ser como ellos assi en aprender la lengua» (Barreira, 1552: 25-27). Por supuesto, tanto Rodrigues como Garupe tienen nociones de la lengua japonesa. Sin embargo, la Compañía fue más allá. Para lograr un mayor acercamiento a la población, los miembros de la compañía comenzaron a adoptar los hábitos alimenticios y de sueño propios de los monjes budistas o bōzu (Lisón, 2005: 38-39). Unos años más tardes, se diría que «los padres primeros por agradar a los japones se bistieron de su avito» (Ruiz, 1587:5v), aludiendo a los atuendos del clero budista. Se estudió en profundidad la vida de Japón, resultando en la publicación de obras como el Sumário dos erros en que os gentios do Japão vivem e de algumas seitas gentílicas en que principalmente confiã (1556), atribuído a Cosme de Torres; el Tratado em que se contêm muito sucinta e abreviadamente algumas contradições e diferenças de constumes entre a gente de Europa e esta província de Japão (1585) de Luís Fróis; o Il cerimoniale per i missionari del Giappone (1581) del propio Alessandro Valignano, entro muchos otros. El objetivo final era la creación de una Iglesia Japonesa, para lo que se abrieron escuelas donde «los niños se ajuntavan tres vezes cada dia a aprender la doctrina xtiana» (Valerregio, 1570: 3v-4). No resulta pretencioso considerar a Ichizo (Yoshi Oida), quien lideraba la comunidad católica de Tomogi antes de la llegada de Rodrigues y Sebastiao, uno de estos alumnos, como tampoco hacerlo con el intérprete (Tadanobu Asano) que Inoue designa para Rodrigues, quien afirma haber estudiado del Padre Francisco Cabral.

Mayor presencia tiene el proceso de sincretismo entre las religiones católica, budista y shintō. La práctica por la que la Compañía hacía uso de términos budistas como Dainichi ${ }^{14}$, con el que se aludía a Dios, o hotoke, que el Padre Luís Fróis asimilaba con el concepto de Santo (Fróis, 1571: 61), así como vestir atuendos propios de los bōzu, son motivos suficientes

13 Para tal propósito, encontramos fundamental la tesis doctoral de Ainhoa Reyes Manzano La Cruz y la Catana: relaciones entre España y Japón (Siglos XVI-XVII) (2014).

14 «Japanese form of the Buddhist deity Vairochana or Mahāvairochana, who represents the highest expression of the godhead in Esoteric Buddhism. In the Tendai and Shingon sects, he is the central figure of the pantheon and the mandalas. He is the supreme Buddha of Light, the ultimate reality without beginning or end» (Frédéric, 2002: 142). 
para considerar que las poblaciones bautizadas entendiesen la nueva fe como una secta más llegada desde la India. Pero la cuestión que los jesuitas vieron con mayor temor fue la de su propia insuficiencia numérica. No fue excepcional que grupos católicos pasaran años sin la presencia de un misionero y carentes de la formación necesaria. Al respecto, Fróis, en su Historia de Japam comentaba que «não seria facil poder-se dizer quantas contradições teve naquella obra» (1982: 369). Es, precisamente, lo ocurrido en Silencio. Las consecuencias podían tener diferentes grados. Aunque de forma muy sintetizada, hay dos momentos en los que la cinta nos pone de manifiesto el escaso grado de evangelización. Al primero de ellos el propio Rodrigues refiere en su fuero interno, cuestionándose si aquellas personas valoraban en mayor medida los objetos simbólicos que les había regalado que la propia fe católica. El segundo lo encontramos durante el bautizo de un recién nacido, a lo que sus padres preguntan convencidos si ya se encuentran en el Paraíso. Lamentablemente, Scorsese decidió no mostrar el caso que mejor ejemplifica este proceso, pues habría significado un obstáculo para el mensaje que el filme transmite en su desenlace. Se trata del sincretismo entre la bodhisattva ${ }^{15}$ Kannon y la María católica (Sindemann, 2001: 125), que sí aparece en la adaptación cinematográfica de Masahiro Shinoda (Chinmoku, 1971) a través de una estatuilla de esta María-Kannon con el Niño entre sus brazos. Este tipo de consecuencias doctrinales fueron extensamente transmitidas a través de la correspondencia jesuita.

Hay, sin embargo, un ente que está presente durante toda la cinta y que presiona, persigue y pone en peligro la misión de Rodrigues y Garupe. En efecto, se trata de la estructura del Estado japonés y el propio Shogunato, personificada a través de un Inquisidor Inoue que se acerca más a otros villanos con tintes sociópatas como el nazi Christoph Waltz en Malditos Bastardos (Tarantino, 2009) que a un funcionario del Período Edo. Esta situación desvincula toda la trama del desarrollo político de Japón, impidiendo que el público pueda hacerse una idea de las causas que han provocado tal situación. Como breve aproximación al complejo proceso interno ocurrido en el archipiélago, lo cierto es que la Compañía de Jesús estuvo siempre relacionada a ojos de las autoridades japonesas con la Corona de Portugal, principal valedora de sus viajes, y, dada la situación bélica que vivía el archipiélago, los daimyō vieron el comercio portugués como un modo de asegurar su fuerza militar (Sansom, 1979: 263-267). De ahí que encontremos una primera etapa de favorecimiento del catolicismo a cambio de la llegada de barcos portugueses a sus puertos, como fue el caso del daimyō Ōtomo Yoshishige (Ōtomo, 1568: 53). Por otro lado, tras producirse la unificación política, la estrecha vinculación del catolicismo con poderes terrenales externos provocó un giro en la política religiosa que comenzó con el decreto aprobado por Hideyoshi en 1987 por el que «todos los P[adr]es y H[e]r[man]os fuesen echados de Japon» (Gómez, 1588: 710). A partir de entonces, se tomó una serie de medidas que fueron desde la ratificación del primer decreto por leyasu Tokugawa en 1614 al cese de las relaciones comerciales con las flotas hispano-portuguesas en 1624, llegando al edicto de prohibición de salida o entrada de cualquier barco y persona de Japón en 1633 por lemitsu Tokugawa (Lanzaco, 2011: 356358). Todo concluyó con la creación, en 1635, del cargo de Shūmon bugyō (Kondo, 1999: 219), un inspector de asuntos religiosos que, en el caso de Nagasaki y como vemos en el filme, estuvo en manos del Inquisidor Inoue-sama.

15 Entes propios de la doctrina Budista que, en un momento determinado, alcanzaron el estado de lluminación para permanecer en el mundo terrenal con el objetivo de ayudar al resto de la Humanidad a alcanzarlo (Lanzaco, 2011: 67). 


\section{CONCLUSIONES}

La representación de Japón que se ha dado en Europa y, después, en todo Occidente a lo largo del tiempo ha ido variando en relación a los factores sociales, culturales y políticos de cada momento. Si bien vemos en sus orígenes un relato fantástico y rodeado de cierto misticismo que le asociaba al mismo tiempo al temor hacia las culturas paganas y las tierras de Oriente, la circunnavegación portuguesa de África y la expansión colonial hacia Asia provocaron un desequilibrio en la concepción que se tenía del mundo a un nivel comparable al del descubrimiento de América.

A partir de entonces, las lejanas y extrañas culturas orientales pasaron a ser una realidad a la que las potencias europeas podían tener acceso y con las que pronto comenzaron los intercambios comerciales, pero también eran un foco donde concentrar los esfuerzos evangelizadores. La Compañía de Jesús se convirtió en el baluarte que permitiría un avance estable allá donde las relaciones diplomáticas y comerciales se produjeran. Sin embargo, el caso de Japón supuso un duro golpe del que la orden religiosa tardó en recuperarse. A excepción del permiso concedido a Holanda para comerciar a través de la isla artificial de Dejima, el archipiélago levantó un férreo cordón sanitario cultural con respecto al exterior que le aisló hasta la segunda mitad del siglo XIX. Para entonces, Europa había cambiado su visión de Japón y, a lo largo del siglo XX, concretamente en el ámbito cinematográfico, se crea una estructura mental que relaciona la sociedad nipona con la disciplina, el orgullo y la falta de humanidad, con un momento álgido durante la II Guerra Mundial.

Silencio pertenece a una tercera fase que engloba multitud de formas de entender el entorno japonés con el elemento común de formar parte de un cine comercial propio de la cultura de masas y la sociedad de consumo. Como tal, no consigue evitar que, pese a buscar una representación fidedigna de los conflictos culturales y los modos en los que las personas del siglo XVII buscaban solucionarlas, termina cayendo en la simplificación cuando decide no mostrar la complejidad del proceso en que se sitúa. Tampoco acierta al transmitir una estructura maniquea de la trama, donde el aparato represivo aparece como una mera herramienta que no desea otra cosa que la eliminación espiritual y física de la Iglesia Católica sin atender a mayor justificación y donde el héroe vence, pese a todo, sin un ápice de adaptación ni cuestionamiento de la doctrina que le acompaña.

Al mismo tiempo, la cinta consigue liberarse de los esquemas que han venido repitiéndose a lo largo de las últimas décadas y que no permitían ver otra interpretación que no entrara en dichos patrones. También cabe considerar la elección de Scorsese por una temática tan arriesgada, alejada de cualquier ámbito popularmente conocido y necesitada de una iniciación previa que acerque al público general a un período de indudable importancia. No sólo porque muestra el primer intento de Europa por tener presencia en Japón, sino porque el actual interés por aquel período histórico y ámbito geográfico parte del atractivo de una sociedad y unas corrientes filosóficas que la mayoría de las ocasiones difieren mucho del verdadero discurso histórico. En conclusión, siendo conscientes de la necesidad de apuntar hacia una narración capaz de abarcar cuestiones de mayor complejidad a las que se limita Silencio, es esta cinta una herramienta excepcional para plantear una nueva forma de hacer un cine comercial alejado de los estereotipos de corte histórico y social hacia una imagen de Japón rica, heterogénea y transversal. 


\section{BIBLIOGRAFÍA CITADA}

Barrenetxea, I., «La posmodernidad y la sociedad japonesa en Lost in Translation», en José María Tápiz (ed.), La Historia a través del Cine: China y Japón en el Siglo XX, Vitoria, Servicio Editorial de la Universidad del País Vasco, 2008, pp. 135-161.

Beauregard, L. P., "Scorsese muestra Silence al papa Francisco», El País,1 de diciembre de 2016; <https://elpais.com/cultura/2016/12/01/actualidad/1480559747_950824.html> [consulta: 02 mayo 2018].

Brinkley, F., A history of the Japanese people from the earliest times to the end of the Meiji era, New York, The Encyclopædia Britannica Company, 1915.

Brody, R., "Martin Scorsese Tests His Limits in Silence», The New Yorker, 27 de diciembre de 2016; <https://www.newyorker.com/culture/richard-brody/martin-scorsese-tests-hislimits-in-silence> [consulta: 24 enero 2018].

Corrêa, M., São Francisco Xavier: Um homem para os demais, Lisboa, CTT Correios de Portugal, 2006.

Crasset, J. [1705], The history of the church of Japan, 2 vols., trad. N. N., London, Gale ECCO, 2010.

Dargis, M., «Review: Questions and Prayers Go Unanswered in Scorsese's Silence», The New York Times, 22 de diciembre de 2016; <https://www.nytimes.com/2016/12/22/movies/ silence-review-martin-scorsese.html> [consulta: 24 enero 2018].

De Gante, F., Informaciones acerca de la vida del Venerable fray Alonso Orozco, 1601-1700, Madrid, Juan Sanz, 1719.

De Torres, C. [1549], Sumário dos erros en que os gentios do Japão vivem e de algumas seitas gentílicas en que principalmente confiã, ed. Juan García Ruiz-de-Medina, Monumenta Historica Japoniae, II, Rome, Institutum Historicum Societatis lesu, 1990.

De Vega, L., Triunfo de la Fee en los reynos del Japón por los años de 1614 y 1615, Madrid, Viuda de Alonso Martin, 1618.

Endō, S., Silencio, Barcelona, Edhasa, 1988.

Frédéric, L., Japan Encyclopedia, Cambridge, Harvard University Press, 2002.

Fróis, L., Carta de 1571 por el Padre Luís Fróis desde Meaco para el Padre Pedro de Almeida, Meaco, Compañía de Jesús, 1571.

- Historia de Japam, 5 vols., ed. José Wicki, S. J., Lisboa, Ministerio da Cultura e Coordenação Científica, 1982-1984.

- [1585], Tratado sobre las contradicciones y diferencias de costumbres entre los europeos y japoneses (1585), ed. trad. Ricardo de la Fuente Ballesteros, Salamanca, Ediciones Universidad de Salamanca, 2003.

Gómez, P., Copia de una carta del P[adr]e P[edr]o Gomez escrita en Japon p[a]ra el P[adre] P[edr] o de Fonseca dela Comp[añi]a de Jesus en Portugal, Japón, Compañía de Jesús, 1588.

Javier, F. [1549], "Carta del Padre M. Francisco», en AA.VV., Copia de vnas cartas del padre mestre Fra[n]cisco y del padre M. Gaspar y otros padres dela compañia de lesu que escriuieron de la India a los hermanos del colegio de lesus de Coimbra. Tresladadas de Portugues en Castellano, recebidas el año de M.D.I.i., Coimbra, João de Barreira e João Álvares, 1551-1552, pp. 19-33.

Kaempfer, E. [1727], The history of Japan. Together with a Description of the Kingdom of Siam, 1690-1692, 3 vols., trad. J. G. Scheuchzer, Glasgow, James MacLehose and Sons, 1906. 
Kondo, A., Japón. Evolución histórica de un pueblo (hasta 1650), Guipúzcoa, Nerea, 1999.

Lanzaco, F., Introducción a la cultura japonesa. Pensamiento y religión, Valladolid, Universidad de Valladolid, 2011.

Lisón, C., La fascinación de la diferencia. La adaptación de los jesuitas al Japón de los samuráis, Madrid, Akal, 2005.

López, F. J., «Entre Geishas y Samurais. La Imagen del Japonés en el Cine Occidental», en AA.V., Alfabetización mediática y Culturas digitales, Sevilla, Universidad de Sevilla, 2010, pp. 1542-1552.

Lucena, J., El Imperio del Sol Naciente (Impresiones de un Viaje a Japón), Barcelona, Establecimiento Tipolitográfico Editorial de Ramón Molinas, 1893.

Oliveira, J. P., «Tokugawa leyasu and the Christian Daimyō during the Crisis Of 1600», Bulletin of Portuguese - Japanese Studies, 7 (2003), pp. 45-71.

Ōtomo, Y., Carta del Rey de Bungo de 1568 para el Padre Melchior Carnero, Bungo, Compañía de Jesús, 1568.

Papinot, E., Historical and Geographical Dictionary of Japan, 2 vols, New York, Frederick Ungar Publishing Co., 1964.

Polo, M., Il Milione, ed. Valeria Bertulocci Pizzorusso, Milán, Adelphi, 1975.

Rosillo, L. «Japón como referente en el cine occidental: entre la proyección condicionada y la variable receptividad», en Anjhara Gómez Aragón (ed.), Japón y Occidente. El Patrimonio Cultural como Punto de Encuentro, Sevilla, Aconcagua Libros, 2016, pp. 707-716.

Ruiz, L. [1623], Relación de los mártires del Japón, ed. Andrés de la Parra, Madrid, Andrés de la Parra, 1624.

Sansom, G., A History of Japan. 1334-1615, 2 vols., Tokyo, Charles E. Tuttle, 1979.

Sicardo, J., Christiandad del Japon, y Dilatada Persecucion que Padecio. Memorias Sacras, de los Martyres de las Ilustres Religiones de Santo Domingo, San Francisco, Compañia de Jesus; y Crecido Numero de Seglares: Y con Especialidad, de los Religiosos del Orden de N. P. S. Augustin, Madrid, Francisco Sanz, Impressor del Reyno, y Portero de Camara de Su Majestad, 1698.

Sindemann, K., "Japanese Buddhism in the 16th century. Letters of the Jesuit Missionaries», Bulletin of Portuguese - Japanese Studies, 2 (2001), pp. 111-133.

Valerregio, A., Carta de 1570 por el Hermano Alexandro Valerregio desde Vochica para un padre, Vochica, Compañía de Jesús, 1570.

Valignano, A. [1583], Historia del principio y progresso de la Compañía de Jesús en las Indias Orientales (1542-64), ed. Joseph Wicki, Rome, Institutum Historicum Societatis lesu, 1944.

[1581], Il cerimoniale per i missionari del Giappone, ed. Josef Franz Schütte, Roma, Edizioni di Storia e Letteratura, 1946. 